\title{
Investigation of the effect of implantation with iron ions on the carbon content in the implanted layer of structural and instrumental materials
}

\author{
Viktor Ovchinnikov ${ }^{1 *}$, Elena Lukyanenko ${ }^{1}$, and Svetlana Yakutina $^{1}$ \\ ${ }^{1}$ Moscow Polytechnic University, 38 B, Semenovskaya st., Moscow, 107023, Russian Federation
}

\begin{abstract}
As part of the ongoing research, iron ions were implanted with targets from armco iron, steels 10,45 , U8 and 30KhGSN2A with a dose of 51017 ion / cm2. Implantation was performed under the conditions of an "oil-free vacuum" obtained through the use of modern turbomolecular pumps. It is shown that for tool steels with a carbon content of $0.8-1.2$ mass. \% the concentration of free carbon in the implanted layer does not exceed 5 at. \%, and for carbon steels upon implantation with a twocomponent ion beam of copper and lead, the concentration of free carbon in the surface layer does not exceed 5 at. $\%$.
\end{abstract}

\section{Introduction}

The development of industry and the increasing complexity of engineering objects place increasing demands on functional materials, in particular, carbon and alloy steels [1-5]. One of the promising methods for improving the physicomechanical characteristics of steels is surface treatment with concentrated energy flows, in particular, plasma treatment, laser treatment, and ion implantation. The improvement of the physicomechanical properties of ion-doped materials is associated with the formation of intermetallic compounds, nanoscale interstitial phases, and the like in the surface layers [6-11].

The problem of increasing the physicomechanical properties of functional materials can be solved by double implantation in the combination "an ion of one metal - an ion of another metal" [12-15]. As a result of this, it is urgent to develop such technologies for the modification of steels that, on the one hand, would be controllable, and on the other hand, would make it possible to obtain a composition and structure in the surface layer that vary over a wide range.

Therefore, the study of the structure, elemental composition, physico-mechanical properties, phase and morphological changes occurring in the surface layers of steels after ion implantation is an urgent and important task.

\footnotetext{
Corresponding author: uchevatkina@yandex.ru
} 


\section{Experimental detail}

As part of the ongoing research, iron ions were implanted with targets from Armco iron, steels 10,45 , U8 and $30 \mathrm{KhGSN} 2 \mathrm{~A}$ with a dose of $5 \cdot 10^{17}$ ion $/ \mathrm{cm}^{2}$. Implantation was performed under the conditions of an "oil-free vacuum" obtained through the use of modern turbomolecular pumps.

The results show that the content of free carbon in the surface layer after implantation is quite well correlated with the carbon content in the target (Fig. 1).

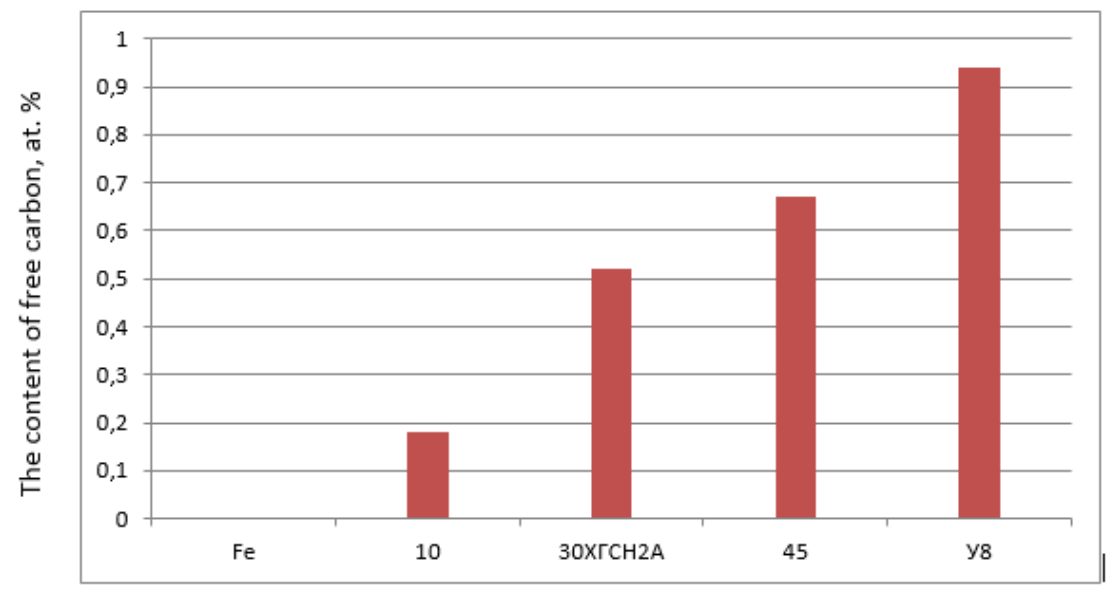

Fig. 1. The influence of the chemical composition of the target on the amount of free carbon in the surface layer after implantation with iron ions

\section{Results and discussion}

An analysis of the obtained data allows us to conclude that ion implantation does not introduce additional carbon into the target (as evidenced by the results on armco-iron). However, in the presence of carbon in the target, implantation with iron ions is accompanied by the formation of free carbon in the surface layer.

The amount of free carbon in the surface layer depends on the chemical composition of the target. With increasing carbon content in the target, the amount of free carbon increases.

When processing with iron ion beams of steels of the studied grades, the structuralphase state of their surface layer changes. If the irradiation regime is maintained so that the samples do not heat above $150^{\circ} \mathrm{C}$, then the initial structure is crushed in the surface layer.

On electron microscopic images of foils prepared from a surface layer treated with a beam of iron ions (Fig. 2), it is clearly seen that both the length and width of the martensitic rails in packets decreases by an average of 2-3 times in the first case. In the microdiffraction patterns, the reflections from the martensitic phase, instead of the point ones, become close to ring ones.

X-ray diffraction analysis (Table 1) also indicates a decrease in the sizes of coherent scattering blocks. The totality of the data obtained indicates the nanostructuring of the martensitic phase in the ion-treated surface layer.

The refinement of the structure is also accompanied by an increase in the dislocation density in martensite crystals up to $(2.5-3.4) \cdot 10^{11} \mathrm{~cm}^{-2}$. Also, the process is accompanied by phase transformations. Presumably - cementite partially decomposes, instead carbide is formed with the same morphology as cementite and free carbon. 
When determining the tribomechanical characteristics of samples from these steels after their treatment with iron-based ion beams, an increase in fatigue life and endurance limit, ultimate tensile and bending strength, microhardness and wear resistance, as well as relative elongation was established. It should be emphasized that, in contrast to the traditional types of steel treatment [16-21], ionic nanostructuring simultaneously increases both the strength and plastic properties of steels. The effect of treatment with beams of ionic complexes is much higher than that of treatment with single-element ionic metal beams.

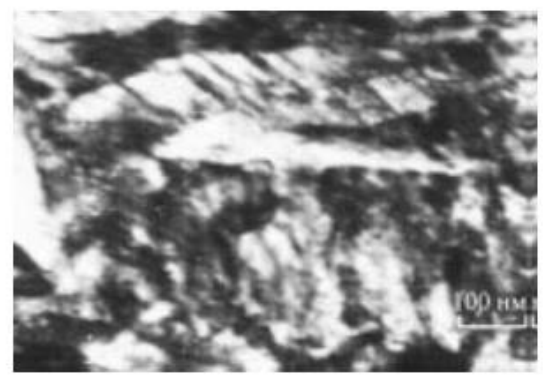

a

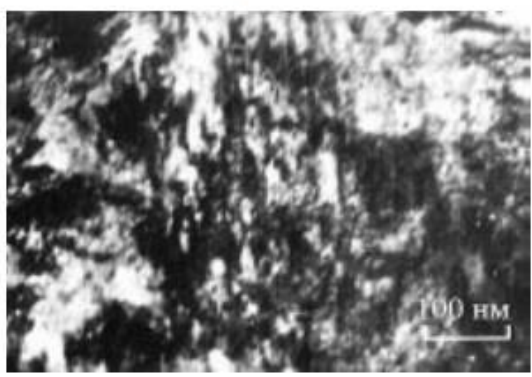

c

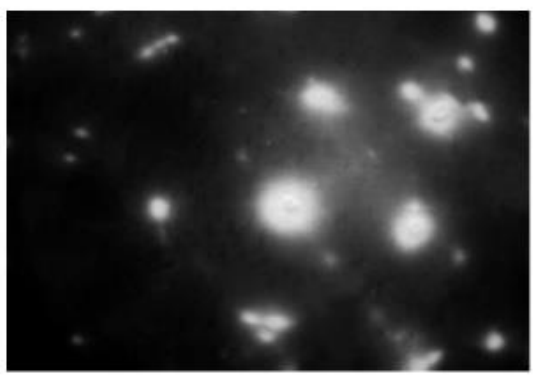

$\mathrm{b}$

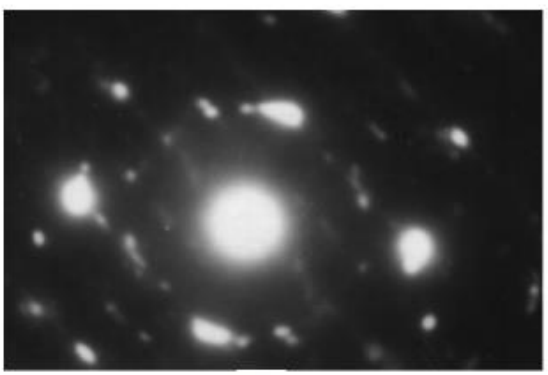

d

Fig. 2. The microstructure of the surface layer of steel 45 in the initial state $(a, b)$ and treated with beams of iron ions $(\mathrm{c}, \mathrm{d})$ at an accelerating voltage of $30 \mathrm{kV}$ and an irradiation dose of $5 \cdot 10^{17}$ ion / $\mathrm{cm}^{2}$.

The increase in wear resistance, hardness and strength properties of the surface layer of carbon and low alloy steels during ionic nanostructuring is associated with the action of four main mechanisms - grain-boundary, dislocation, dispersion, and solid-solution hardening. The ratio of their contributions is determined by the type of ion beam, the processing mode, and the grade of steel.

Despite the same accelerating voltage and radiation dose, the elemental composition of the ion beam affects not only the projective range, but also the actual number of ions embedded in the surface layer.

The magnitude of the effect of increasing the tribomechanical properties depending on the type of implanted ions is consistent with the total area under the concentration profiles, which is proportional to the total number of ions embedded in the surface layer. The increase in ductility and fatigue life is due to an increase in the shear instability of the nanostructured surface layer, which relaxes subsurface stress concentrators due to accommodation deformation. As a result, the development of microcracks is inhibited and the destruction of the sample is slowed down.

Based on a study of the nature of the action of ion beams on the mechanical properties of carbon and low alloy structural steels at temperatures below $150{ }^{\circ} \mathrm{C}$, the effect of ionbeam nanostructuring of the surface layer was experimentally established, which, in 
contrast to traditional hardening methods, leads to a simultaneous increase in microhardness and strength, on the one hand, wear resistance, on the other hand, ductility and fatigue life. It reaches its greatest value when treating the surface with high-energy beams of ionic complexes based on metals with a large atomic radius than that of iron, which, due to their low mass, sputter the surface layer weakly, but penetrate to a greater depth, causing strong distortions of the crystal lattice of the material and creating a high stress gradient.

The effect is associated with the grinding of martensite to a nanoscale level due to radiation-induced recrystallization of the surface layer of steel. At the same time, a significant increase in the density of dislocations, a change in the particles of the initial phases, and the formation of fine particles of new phases that stabilize a highly defective nanostructure occur in the surface layer. The magnitude of the effect and the optimal radiation dose at which it reaches a maximum are determined by the composition of the ion beam and the type of material being processed.

To experimentally evaluate the dependence of the concentration of free carbon in the implanted layer when using a multicomponent ion beam for implantation, steels with different carbon contents were used as targets. The carbon content and grade of steels used as targets are presented in table. 1 .

Table 1. The carbon content of steels used as targets.

\begin{tabular}{|c|c|c|c|c|c|c|}
\hline \multicolumn{7}{|c|}{ The carbon content in steel, wt. \% } \\
\hline 10 & 20 & 45 & 60 & y8 & Y10 & Y12 \\
\hline $0.07-0.14$ & $0.17-0.24$ & $0.42-0.59$ & $0.55-0,63$ & $0.76-0.83$ & $0.96-1.03$ & $1.16-1.23$ \\
\hline
\end{tabular}

Ion implantation was carried out by a two-component ion beam containing copper and lead ions, using a $64 \% \mathrm{Cu}+36 \% \mathrm{~Pb}$ monotectic alloy implant cathode. The implantation dose was $5 \cdot 10^{17}$ ion $/ \mathrm{cm}^{2}$. The results of determining the concentration of free carbon in the implanted layer are presented in Figure 3.

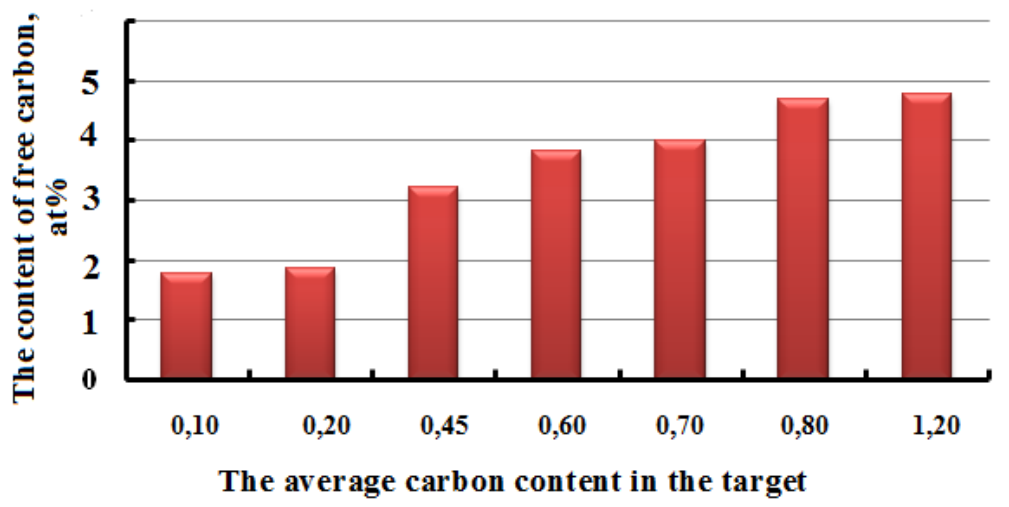

Fig. 3. Free carbon content in implanted steel layer with different carbon content.

An analysis of the results presented in Figure 1.3 shows that after implantation in steels with a carbon content of $0.10-0.20$, the content of free carbon in the implanted layer does not exceed 2 at. $\%$

In steels with a carbon content of 0.4-0.7 mass. \% free carbon content in the implanted layer is $3.2-4$ at. $\%$

For tool steels with a carbon content of $0.8-1.2$ mass. \% the concentration of free carbon in the implanted layer does not exceed 5 at. \%. 


\section{Conclusions}

An analysis of the results presented in Figure 1.3 shows that after implantation in steels with a carbon content of $0.10-0.20$, the content of free carbon in the implanted layer does not exceed 2 at. $\%$

In steels with a carbon content of $0.4-0.7$ mass. \% free carbon content in the implanted layer is $3.2-4$ at. \%

For tool steels with a carbon content of $0.8-1.2$ mass. $\%$ the concentration of free carbon in the implanted layer does not exceed 5 at. \%

This work was carried out as part of the state task of the Ministry of Education and Science of Russia "The influence of magnetic fields and ion implantation on the structure, chemical composition and properties of titanium, aluminum alloys and elementary semiconductors"

\section{References}

1. S.L. Kakani, Materials Science. New Age International, 656 (2006)

2. Y.Y. Chen, H.J. Tzeng, L.I. Wei, L.H. Wang, J.C. Oung, H.C. Shih, Corrosion Science, 47(4), 1001-1021 (2005)

3. J. Keisler, O.K. Chopra, W.J. Shack, Div. of Engineering Technology; Argonne National Lab., IL NUREG / CR-6335; ANL-95/15 / (1995)

4. W.M. Garrison, JOM, 42(5), 20-24 (1990)

5. M.Z. Ibrahim, A.A. Sarkhan, F. Yusuf, M. Hamdi. Review article. Journal of Alloys and Compounds, 714, 636-667 (2017)

6. D.I. Proskurovsky, V.P. Rotshtein, G.E. Technology of Surfaces and Coatings, 96 (1), 117-122 (1997)

7. S. Konovalov, H. Chen, V. Sarychev, S. Nevsky, V. Gromov, M. Trtika, Metals, 7 (1), 4. (2017)

8. S.N. Brother, S.V. Sokolov. Physical surface engineering, 10(2), 138-161 (2012)

9. D.N. Korotaev, E.V. Ivanova, Promising Materials, 2, 98-102 (2011)

10. A.V. Kolomeychenko, Orel: Publishing house Orel GAU, 2013, 230 (2011)

11. V.P. Perevertov, I.K. Andronchev, M.M. Abulkasimov, Proceedings of the International Symposium "Reliability and Quality", 1, (2015)

12. R.M. Khisamutdinov, V.V. Zvezdin, I.Kh. Israfilov, R.R. Saubanov, A.A. Spirin, R.R. Rakhimov, In the physical journal: conference series. IOP Publishing, 669 (1), 012024 (2016)

13. G. Krauss, Heat Treatment Journal, 9 (2), 81-89 (1992)

14. M.K. Lei, Z.L. Zhang, Journal of Vacuum Science and Technology A: Vacuum, Surfaces and Films, 15 (2), 421-427 (1997)

15. P. Sioshansi, Materials Science and Engineering, 90, 373-383 (1987)

16. D. Tobola, V. Brostov, K. Chekhovsky, P. Rusek, Wear, 382, 29-39 (2017)

17. H.A. Youssef, John Wiley and Sons, 275 (2015)

18 S.N. Polyansky, S.V. Butakov, V.A. Alexandrov, I.S. Olkov, Agrarian Bulletin of the Urals, 12 (142) (2015)

19. A.M. Guryev, L.G. Voroshnin, Yu.P. Kharaev, B.D. Lygdenov, E.V. Chernykh, Fundamental problems of modern materials science, 2 (3), 37-45 (2005)

20. A.P. Veselovsky, S.V. Kubarsep, L.A. Ushomirskaya, Metalworking, (4), 29-31 (2001)

21. A.M. Guriev, B.D. Lygdenov, O.A. Vlasova, Basic research, (8), 10 (2008) 